\title{
Numerical Investigation of Spalled Particle Behavior Ejected from an Ablator Surface
}

\author{
By Sohey NozAwA, Hisashi KiHARA and Ken-ichi ABE \\ Department of Aeronautics and Astronautics, Kyushu University, Fukuoka, Japan
}

(Received June 16th, 2009)

\begin{abstract}
During ablation experiments in an arc-heated facility, the presence of spalled particles has been observed upstream of a detached shock wave or a stagnation-point boundary layer. In the past experiments using spectroscopic measurement for nitrogen arc-jet, the $\mathrm{CN}$ violet band spectra owing to the spallation particles ejected from the ablator were observed upstream of the shock layer. Based on this fact, in this study, the flight path of a single spallation particle ejected into a nonequilibrium flow field is numerically analyzed and the particle properties are obtained. The simulation is carried out about a solid particle ejected vertically from the front surface of an ablator, including various initial speeds, sizes, and positions. Moreover, by classifying the obtained results, the particle behavior is carefully investigated and the possibility of a particle being observed upstream of a shock wave is discussed.
\end{abstract}

Key Words: Ablation, Spallation, Particle, Trajectory

\section{Nomenclature}

$u \quad:$ velocity of $\mathrm{X}$-axis

$v \quad:$ velocity of $\mathrm{Y}$-axis

$U_{R} \quad: \quad$ relative velocity between particle and gas

$C_{D} \quad$ : drag coefficient

$D$ : diameter of particle

$T \quad$ : Temperature

$C_{m} \quad: \quad$ specific heat of particle

$\varepsilon \quad: \quad$ emittance of particle

$\Delta G^{\circ} \quad$ : Gibbs free energy

$\mathrm{Nu}$ : Nusselt number

$\sigma \quad:$ Stefan-Boltzmann number

$\lambda \quad:$ thermal conductivity

$\dot{m} \quad$ : mass-losing rate of particle

$\alpha \quad:$ vaporization coefficient

$P \quad: \quad$ equilibrium steam pressure

$M_{i} \quad$ : molecular mass

Subscripts

$$
\begin{array}{lll}
\mathrm{p} & : & \text { particle } \\
\mathrm{g} & : & \text { gas } \\
\mathrm{i} & : & \text { species }
\end{array}
$$

\section{Introduction}

During the planetary entry at high altitude, a reentry vehicle encounters severe aerodynamic heating by convection and radiation. As an effective thermal protection method for hypersonic vehicle, the ablation is well known. So far, the ablation system was equipped on several space-explorer vehicles. Among them, for the Pioneer-Venus and the Galileo probe, the recession rate and the temperature profiles in the heat shield were measured and compared with theoretical calculations. It was found from the comparison that their heating/ablating rates were over-predicted at the stagnation point, while they were under-predicted in the downstream region $^{1,2)}$. These facts suggest that there still remains unclear mechanism which increases heat-transfer rates in the downstream region. One possible mechanism is spallation, which is the phenomenon that solid carbon particles are ejected from the ablator surface.

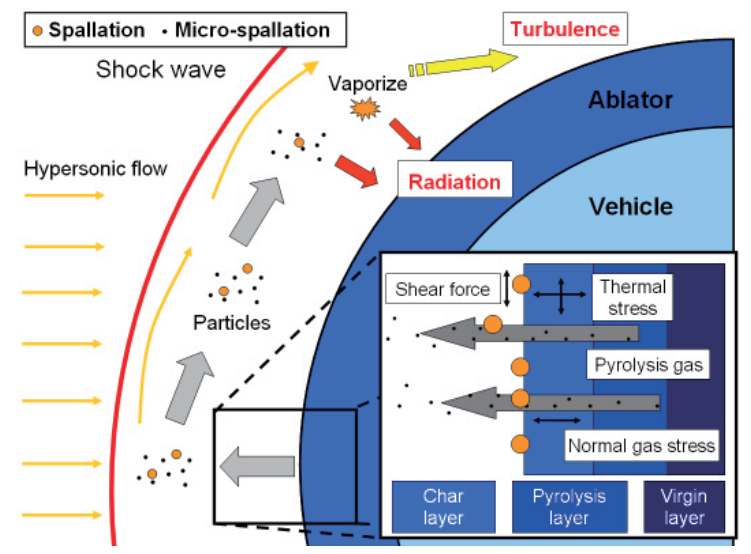

Fig. 1. Schematic view of spallation phenomena.

Figure 1 shows a schematic view of the spallation phenomena. The spallation particles in a carbon ablator are likely to be generated through two different physical phenomena. First, during the pyrolysis process of the ablator, soot may be formed from the pyrolysis gas. Second, the carbon fibers forming the ablator matrix may break in fragment, due to the combination of thermal stress, normal gas stress of pyrolysis gas, and shear stress caused by the flow on the ablator surface. For both the cases, generated particles are pushed out by the pyrolysis-gas pressure and then ejected 
from the ablator surface, together with the pyrolysis gas. During the flight in the high temperature region behind the shock wave, the ejected particle may be heated. Radiation from the particle, its vaporized gas and turbulence generated by the particle may cause the increase of heat-transfer rate in the downstream region.

On the other hand, several research groups have tried to reveal this challenging problem. In the past, the presence of spallation particles has been observed in many experiments. For optical measurements, it was seen in the works of Schneider et al. ${ }^{3)}$ and Lundell et al. ${ }^{4)}$ using gas dynamic laser. For spectroscopic measurements of Yoshinaka et al. ${ }^{5)}$ and Kihara et al. ${ }^{6}$ using arc-heated wind tunnel, radiation emitted from a spallation particle has been measured in the region upstream of the shock wave. Moreover, Raiche et al. ${ }^{7)}$ measured laser attenuation in front of the ablator surface, and Park et al. ${ }^{8)}$ estimated the range of initial velocity for various particle diameters from their results.

Recently, new ablator materials named Phenolic Impregnated Carbon Ablators (PICA) ${ }^{10)}$ by NASA and super lightweight ablator by $\mathrm{JAXA}^{11)}$ are being developed for reentry mission. In order to design such lightweight ablators more effectively, it is indispensable to investigate the phenomena caused by spallation particles in more detail. For this purpose, numerical simulation is now promising way to predict such complex phenomena. As for the numerical approach, it is known that Davis et al. ${ }^{9)}$ calculated the trajectory of a spallation particle ejected from the ablator surface of Galileo probe by using particle parameters that were estimated from optical measurement by Lundell et al. ${ }^{4)}$. It is expected that this approach is also useful for wide range of ground-experiment conditions with arc-heated wind tunnel.

Based on this background, in this study, the flight path of a single spallation particle ejected into an arc-heated nonequilibrium flow field is simulated under various conditions of initial speed, size and position. By processing the obtained data, we tried to categorize the particle behavior into several patterns if the particle is observable at the spectroscopic measurement points confirmed previously. Furthermore, the particle behavior is discussed.

\section{Experiments}

In this study, the spectroscopic experiment performed by Kihara et al. ${ }^{6}$ is chosen for comparison. The schematic view of the experiment is shown in Fig. 2. The $20 \mathrm{~kW}$ arc-heated wind tunnel at Kyushu University was used for generating an arc jet of argon, nitrogen or air. The ablator was made of carbon-phenoric, being $30 \mathrm{~mm}$ in diameter and $50 \mathrm{~mm}$ in length. It was placed at the position of $80 \mathrm{~mm}$ downstream from the nozzle exit and radiation was measured at four points as shown in Fig. 2. Spectroscopic measurements were conducted at the locations of $1 \mathrm{~mm}$ and $19 \mathrm{~mm}$ upstream from the ablator. Since the latter position was outside of a shock layer, it was expected that the behavior of spalled particles penetrating the shock layer could be revealed. In the argon arc-jet case, the spectra of $\mathrm{C}$ band was identified, while the spectra of $\mathrm{CN}$ violet band was identified in the nitrogen and air arc-jet cases. Although $\mathrm{C}$ and $\mathrm{CN}$ can be regarded as a product from a carbonaceous ablator, it is generally difficult for them to penetrate the shock wave. Therefore, it is considered that they are generated by the reactions on the surface of a spalled carbon particle. Such being the case, in this analysis, it is one of the important discussion points to verify if a particle can reach the measurement points shown in Fig. 2, in particular, in the region upstream of the shock layer.

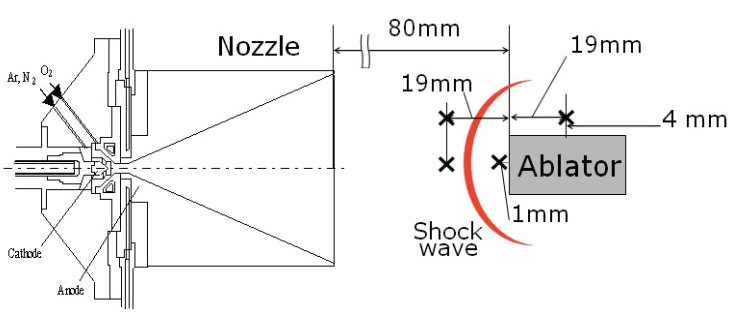

Fig. 2. Schematic view of spectroscopic measurement.

\section{Trajectory Analysis of Spallation Particles}

\subsection{Flow field around ablator}

In the present experiments, the $\mathrm{CN}$ violet band spectra owing to the spallation particles, which are ejected from the ablator, were observed upstream of the shock layer. Based on this evidence, the flight path of a single particle is numerically analyzed. For this purpose, the experimental flow field over an ablator model was numerically reconstructed using the computational code of a thermochemical nonequilibrium flow analysis. The computational domain was $120 \mathrm{~mm} \times 125 \mathrm{~mm}$ and the upstream boundary coincides with the nozzle exit. Grid nodes of $120 \times 114$ were put inside the domain, being dense in the vicinity of the ablator wall. In this calculation, no pyrolysis gas was ejected from the ablator surface for simplicity. The surface temperature of ablator was assumed to be in radiate equilibrium to the flow field. The nozzle-exit conditions were determined from the computational results for the nonequilibrium nozzle flow ${ }^{12}$.

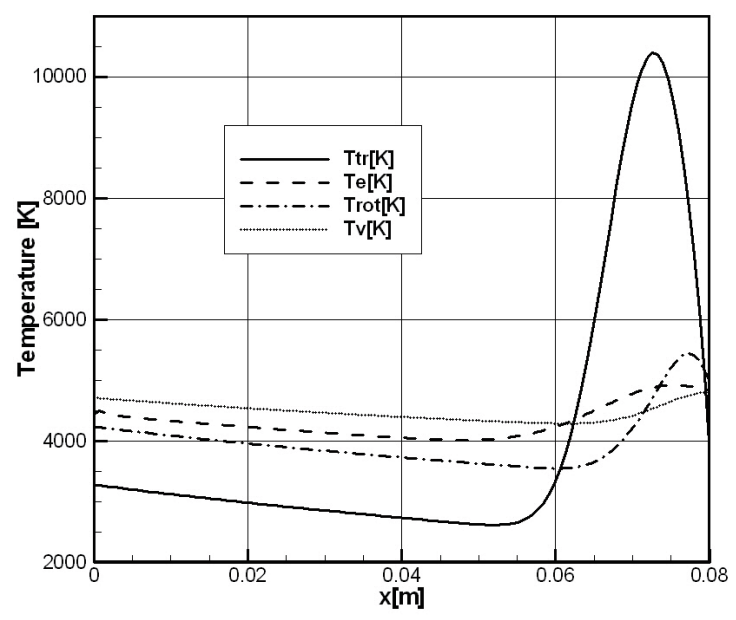

Fig. 3. On-axis temperature profile of the flow field. The point of $0.08 \mathrm{~m}$ is stagnation point of ablator. 
Figure 3 shows on-axis temperature profile. The temperature elevation around the point of $0.07 \mathrm{~m}$ is caused by the compression of the detached shock. It can be seen that the translational temperature reaches $10000 \mathrm{~K}$, so that the particles in this high temperature region are expected to be strongly heated.

\subsection{Basic assumption}

For the trajectory analysis of spallation particles, the following assumptions are considered to simplify the system of equations that describes the particle behavior.

- The particle is spherical solid carbon.

- The particle is ejected normally from the ablator surface.

- The particle keeps spherical shape.

- The flow field is not influenced by solid particles.

- The particle has uniform specific heat and has no temperature distribution inside the particle.

- The particle radiates from the surface, while the gas radiation into the particle is negligible.

- Sublimation on the particle surface is considered, with which the particle diameter decreases.

- If the particle diameter becomes less than 0 , the particle is regarded to vaporize completely.

- The initial particle temperature is set equal to the surface temperature of the ablator assumed from the corresponding experiment, i.e., $2000 \mathrm{~K}$.

\subsection{Fundamental equations}

The motion of a particle in the axial direction can be described by

$$
\frac{4}{3} \pi\left(\frac{D}{2}\right)^{3} \rho_{m} \frac{d u_{p}}{d t}=C_{D} \frac{1}{2} \rho\left(u_{g}-u_{p}\right) U_{R} \pi\left(\frac{D}{2}\right)^{2}
$$

Note that the motion of a particle in the radial direction can be written in a similar form ${ }^{13)}$.

There are three heat-transfer rate terms to be considered: $q_{\text {sub }}$, the rate of sublimation heat transfer from a particle. $q_{\text {rad }}$, the rate of radiation heat transfer from a particle. $q_{c o n v}$, the rate of convective heat transfer into a particle. Thus, the energy equation of a particle is expressed by

$$
\frac{4}{3} \pi\left(\frac{D}{2}\right)^{3} \rho_{m} C_{m} \frac{d T}{d t}+q_{s u b}+q_{r a d}=q_{c o n v}
$$

In this study, $q_{\text {sub }}$ is evaluated by the mass-losing rate for each species multiplied by the Gibbs energy of formation $\Delta G^{\circ}$ over the particle surface.

$$
q_{\text {sub }}=\Delta G^{\circ} \pi D^{2} \dot{m}_{\text {total }}
$$

The $\Delta G^{\circ}$ is interpolated from the JANAF tables ${ }^{14)}$ for each particle temperature $T_{p}$. The quantity $q_{\text {rad }}$ is given by the Stefan-Boltzman law summed over the particle surface. As for the emissivity, the value of solid carbon $(=0.8)$ was used.

The quantity $q_{\text {conv }}$ is given as

$$
q_{\text {rad }}=\varepsilon \sigma T_{p}^{4} \pi D^{2}
$$

$$
q_{\text {conv }}=\pi N u \lambda D\left(T_{g}-T_{p}\right)
$$

Thermal conductivity of the flow field $\lambda$ is obtained directly from the computational results of the flow field. In Eq. (5), the gas temperature is set equal to the translational temperature, i.e., $T_{g}=T_{t r}$.

\section{Evaluation of Parameters}

In order to obtain the values of $C_{D}, N u$ and $\dot{m}$, it is necessary to integrate the equations.

\subsection{Drag coefficient}

For small particles, rarefaction effects are dominant. Thus, in this calculation, the drag coefficient was evaluated by Henderson's ${ }^{15)}$ equation. The equation presented by Henderson for spheres is suitable for wide range of subsonic flow regimes, as well as for molecular flows at Mach number $M_{\mathrm{Re}}$ up to 6, where $M_{\mathrm{Re}}$ is evaluated by the relative velocity between a particle and the surrounding gas. Drag coefficient is evaluated as a function of $M_{\mathrm{Re}}$, the particle Reynolds number $\operatorname{Re}_{g}$ and the temperature ratio between a particle and the surrounding gas. For subsonic flows, $C_{D}$ was given by a simplified Stokes-Oseen equation. In regions of $M_{\mathrm{Re}}>1.75, M_{\mathrm{Re}}$ and $\mathrm{Re}_{p}$ were regarded as the free stream condition, i.e. $M_{\mathrm{Re}}=$ $M_{g}$ and $\operatorname{Re}_{p}=\mathrm{Re}_{g}$. In medium Mach-number regions, $C_{D}$ is given by interpolating the abovementioned values.

\subsection{Nusselt number}

Because of the abovementioned reason, Nusselt number: $\mathrm{Nu}$ is taken from the work of Carlson and Hogland ${ }^{16)}$ that includes rarefaction effect. In this model, $\mathrm{Nu}$ is described as a function of $M_{\mathrm{Re}}$ and $\mathrm{Re}_{p}$.

\subsection{Mass-losing rate of particle surface}

The following sublimation reactions are supposed on the surface of a particle.

$$
\begin{aligned}
& C \rightarrow C \text { (gas) } \\
& C \rightarrow C_{2} \\
& C \rightarrow C_{3}
\end{aligned}
$$

Thus, the mass-losing rate from a particle surface ${ }^{17)}$ is expressed by

$$
\dot{m}_{i}=\sum_{i=1}^{3} \alpha_{i} P_{i}\left(T_{p}\right)\left(\frac{M_{i}}{2 \pi R T_{p}}\right)^{1 / 2}
$$

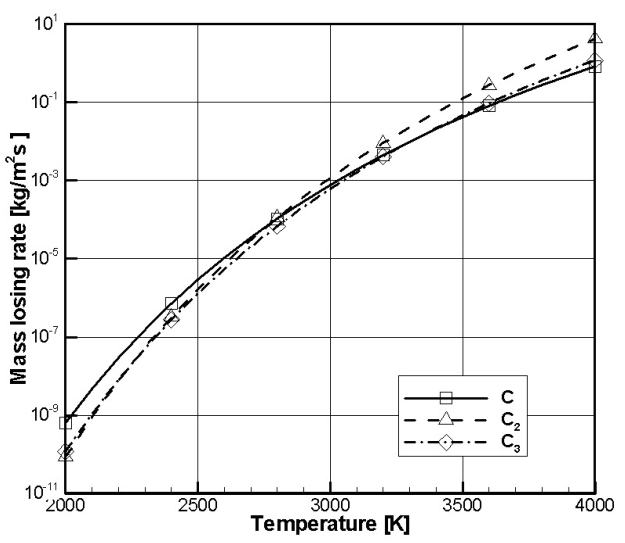

Fig. 4. Mass-losing rate of carbon surface. Carbon species: $\mathrm{C}, \mathrm{C}_{2}, \mathrm{C}_{3}$.

Figure 4 shows the mass-losing rate profiles for temperature. As is shown later, sublimation effect for micro-order particles is found to start at around $3500 \mathrm{~K}$. Although $\mathrm{C}$ (gas) is dominant first, $\mathrm{C}_{2}$ becomes more dominant at around $3000 \mathrm{~K}$. 


\section{Evaluation of Particle Behavior}

For evaluating a particle behavior, if the particle reaches the area of Mach number exceeding 1 in front of an ablator, the particle is assumed to reach the region upstream of the shock wave. In this study, particles with the diameter range of 1$50 \mu \mathrm{m}$ are ejected at 4 points $(3,6,9,12 \mathrm{~mm}$ from the center axis) with the initial velocity increasing by $0.5 \mathrm{~m} / \mathrm{s}$. The obtained results are classified for the following 6 patterns:

[A] Vaporized, not penetrate the shock

[B] Vaporized, not pushed back

[C] Vaporized, pushed back after penetrating the shock

[D] Turn back to the probe surface after penetrating the shock

[E] Flow away out of the field after penetrating the shock

[F] Flow away out of the field, not penetrate the shock

Generally, for the cases of [C], [D] and [E], a particle is expected to be observable at a spectroscopic measurement point in the region upstream of a shock wave.

\section{Results and Discussion}

\subsection{Particle trajectory}

Park et al., ${ }^{8)}$ made the particle-trajectory analysis at the stagnation-point stream line and revealed that a particle with the diameter of $20 \mu \mathrm{m}$ could reach the region upstream of the shock layer if it was ejected at a velocity larger than $12 \mathrm{~m} / \mathrm{s}$. Their results of the particle diameter and velocity were adopted for reference in the present calculation of particle trajectory.

Figure 5 shows the trajectories of spallation particles with the diameter of $40 \mu \mathrm{m}$ and $100 \mu \mathrm{m}$. The particles were ejected at three initial velocities regarded as maximum, reference-value and minimum ones $\left(D_{0}=40 \mu \mathrm{m}: 13,18,25 \mathrm{~m} / \mathrm{s}\right.$, $\left.\mathrm{D}_{0}=100 \mu \mathrm{m}: 8.5,12,17 \mathrm{~m} / \mathrm{s}\right)$. The ejected positions are $6 \mathrm{~mm}$ from the center axis for cases (a) and (c), and $9 \mathrm{~mm}$ for case (b). It is seen that the particles ejected at the minimum velocity in cases (a) and (b) vaporize at high temperature region behind the shock. On the other hand, only for case (c), the particle flows away out of the flow field without complete vaporization. Among the reference-velocity cases, the particle is pushed back by the flow in case (a), finally turns back to the probe surface. On the other hand, in cases (b) and (c) for reference velocity and all the cases for maximum velocity, the particle flows away out of the flow field without complete vaporization. In particular, it is found that in case (b), the ejected particle is passing close to the measurement point in the region upstream of the shock wave and upward of the ablator. This fact may indicate the possibility that the spectroscopic measurement can identify the band spectra emitted from the spalled particle.

In order to investigate the phenomena of spalled particles in detail, the particle temperature and energy during the flight were also calculated. The temperature time history of the particle ejected at reference initial velocity for the particle diameter of $40 \mu \mathrm{m}$ are illustrated in Figs. 6 and 7, where the former is for case (a) and the latter is for case (b), respectively.
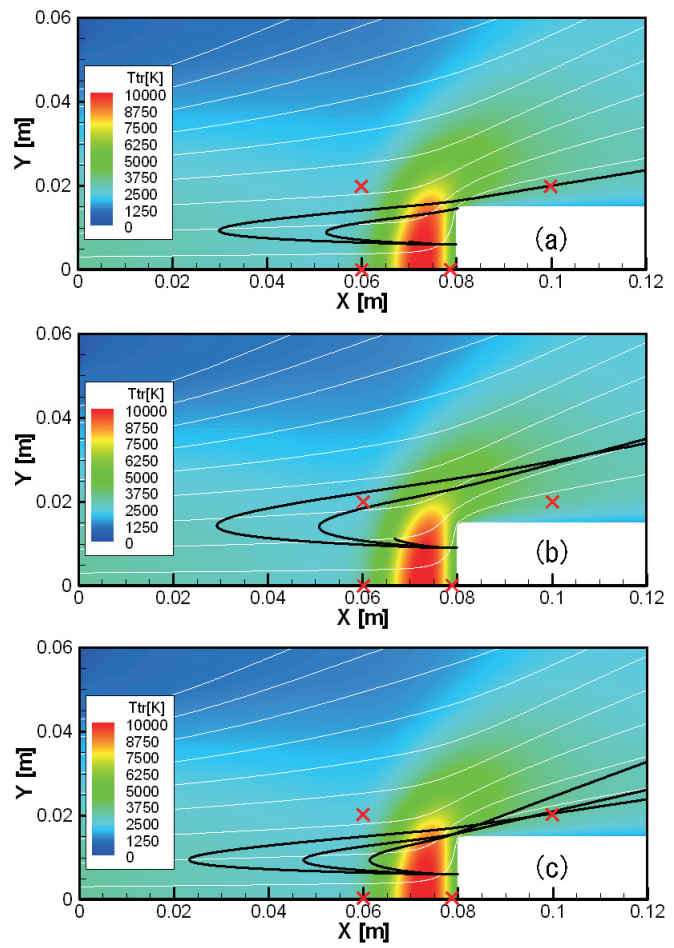

Fig. 5. Comparison of particle trajectories for various initial positions, velocities and diameters. (a): $\mathrm{y}_{0}=6 \mathrm{~mm}, \mathrm{D}_{0}=40 \mu \mathrm{m}$, (b): $\mathrm{y}_{0}=9 \mathrm{~mm}$, $\mathrm{D}_{0}=40 \mu \mathrm{m}$, (c): $\mathrm{y}_{0}=6 \mathrm{~mm}, \mathrm{D}_{0}=100 \mu \mathrm{m}$. Initial velocity, (a), (b): 13, 18, $25 \mathrm{~m} / \mathrm{s},(\mathrm{c}): 8.5,12,17 \mathrm{~m} / \mathrm{s}$.

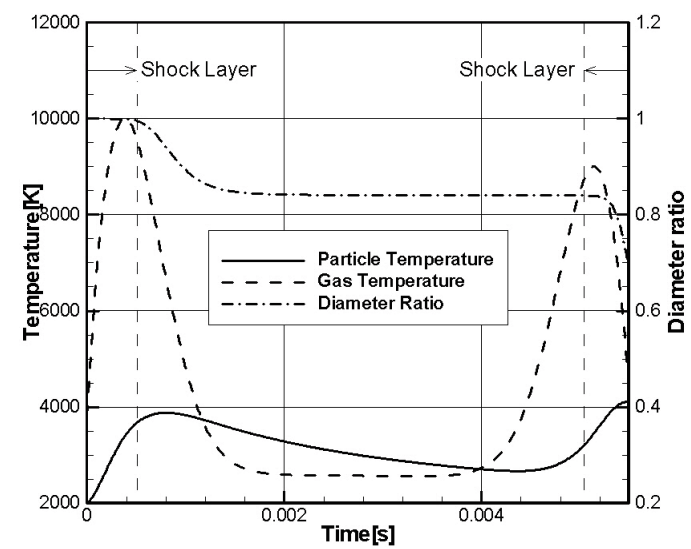

Fig. 6. Time history of temperature and diameter ratio for reference initial velocity $(18 \mathrm{~m} / \mathrm{s})$ in case $(a): \mathrm{y}_{0}=6 \mathrm{~mm}, \mathrm{D}_{0}=40 \mu \mathrm{m}$.

It is found that the ejected particle is rapidly heated in the high temperature region behind the shock wave and thus sublimation occurs on the particle surface, resulting in the decrease of its diameter. For case (a), after rapid decrease of the diameter by the sublimation, the particle penetrates the shock wave and its size is kept almost constant in the upstream region. The particle is, however, pushed back to the high temperature region by the main flow and then heated again, finally turns back to probe surface with $70 \%$ of initial diameter. On the other hand, for case (b), it is not vaporized completely, finally flowing away out of the flow field with $95 \%$ of the initial size being kept. 


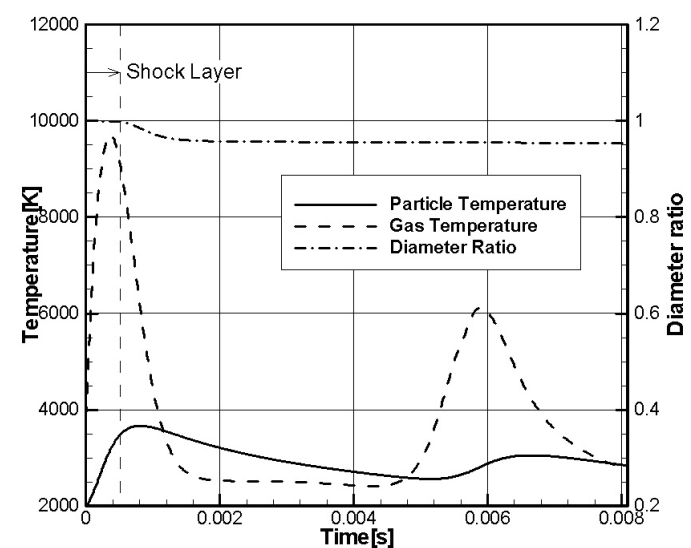

Fig. 7. Time history of temperature and diameter ratio for reference initial velocity $(18 \mathrm{~m} / \mathrm{s})$ in case (b) : $\mathrm{y}_{0}=9 \mathrm{~mm}, \mathrm{D}_{0}=40 \mu \mathrm{m}$.

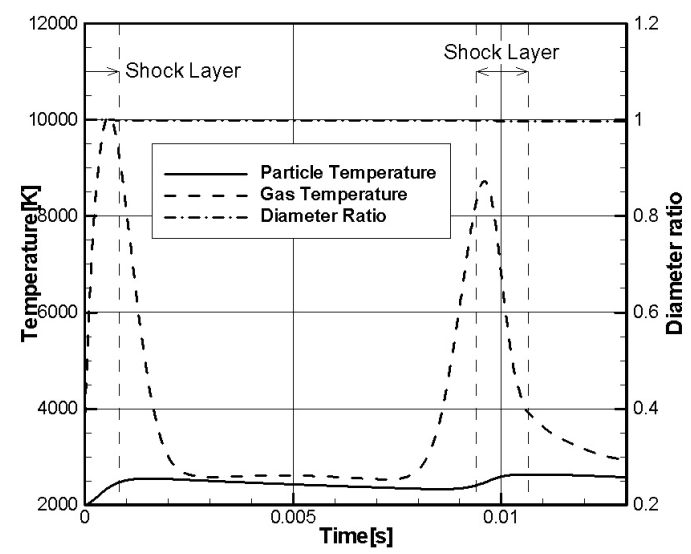

Fig. 8. Time history of temperature and diameter ratio for reference initial velocity $(12 \mathrm{~m} / \mathrm{s})$ in case $(\mathrm{c}): \mathrm{y}_{0}=6 \mathrm{~mm}, \mathrm{D}_{0}=100 \mu \mathrm{m}$.

For comparison, temperature history of the particle with $100 \mu \mathrm{m}$ in diameter ejected at $6 \mathrm{~mm}$ for reference initial velocity $(12 \mathrm{~m} / \mathrm{s})$ is illustrated in Fig. 8. Because of large volume compared with the other cases, the particle temperature does not rise very much. Strong radiation from a larger surface may be considered as a reason for this fact. The particle diameter does not decrease at all, which means almost no sublimation on the particle surface. Under this condition, even if the ejected particle penetrates the shock wave and reaches a measurement point, it is very difficult to identify the presence of the particle by the spectroscopic measurement. From this discussion, the particle diameter that could be observed in the past experiments is expected to be less than $100 \mu \mathrm{m}$.

The energy histories of the particle for case (b) ejected at reference initial velocity is shown in Fig. 9. It is seen that during the flight in the high temperature region behind the shock wave, convection heating is dominant and the particle temperature rises, owing to which the radiation from the particle surface also increases. As illustrated in Figs. 6 and 7, the sublimation is effective for decreasing the particle diameter in case of small particles. The particle-temperature profile shows second peak, where the temperature becomes as high as that of first peak. As seen in Fig. 9, however, both convection heating and radiation heating are almost half of the first peak. This is caused by the decrease of the surface area, the fact which may indicate importance of introducing sublimation effect properly. It is notable that as seen in Fig. 9, the sublimation is almost ineffective for heat balance of the particle.

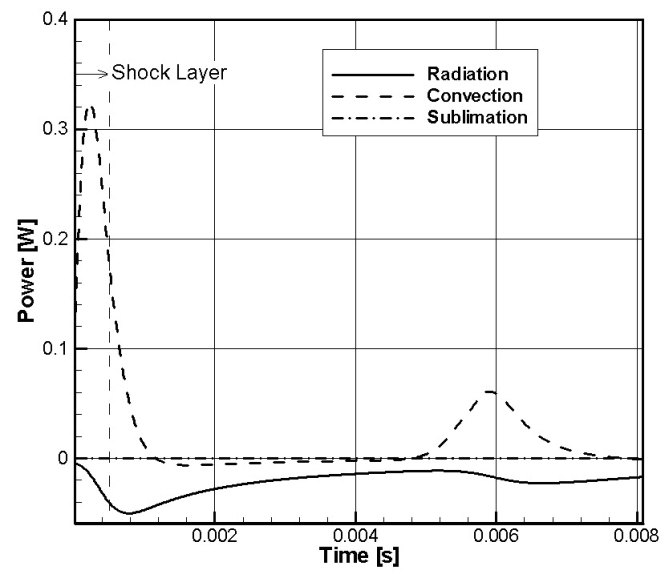

Fig. 9. Time history of energy balance for reference initial velocity $(18 \mathrm{~m} / \mathrm{s})$ in case $(\mathrm{b}): \mathrm{y}_{0}=9 \mathrm{~mm}, \mathrm{D}_{0}=40 \mu \mathrm{m}$.

\subsection{Evaluation of particle behavior}

Table 1 summarizes the particle behavior for various ejected positions and velocities for the diameter of $40 \mu \mathrm{m}$. At around the center axis, the high temperature region is broad, so small particles cannot penetrate the shock wave ([A], [B]). In the outside region, however, many cases indicate that the particles can penetrate the shock wave. For this diameter, no case was confirmed where the particle flows away out of the flow field.

Table 1. Classification of particle behaviors for $\mathrm{D}=40 \mu \mathrm{m}(\mathrm{m} / \mathrm{s})$.In cases $[\mathrm{C}],[\mathrm{D}]$ and $[\mathrm{E}]$, observable at spectroscopic measurement point.

\begin{tabular}{|c|c|c|c|c|c|c|}
\hline & {$[\mathrm{A}]$} & {$[\mathrm{B}]$} & {$[\mathrm{C}]$} & {$[\mathrm{D}]$} & {$[\mathrm{E}]$} & {$[\mathrm{F}]$} \\
\hline $3 \mathrm{~mm}$ & $13 \sim 13.5$ & $\sim 16.5$ & $\sim 20$ & $\sim 25$ & & \\
\hline $6 \mathrm{~mm}$ & & $13 \sim 15$ & $\sim 17.5$ & 18 & $\sim 25$ & \\
\hline $9 \mathrm{~mm}$ & & 13 & $\sim 14$ & & $\sim 25$ & \\
\hline $12 \mathrm{~mm}$ & & & & & $13 \sim 25$ & \\
\hline
\end{tabular}

Further investigations were carried out for various particle diameters. Figure 10 compares the present results with those of Park et al. ${ }^{8)}$ for minimum initial velocity penetrating the shock wave. As the particle diameter increases, the minimum initial velocity penetrating the shock wave rapidly decreases. For the diameter over $30 \mu \mathrm{m}$, minimum initial velocity penetrating the shock wave is not so different from the velocity range predicted by Park et al. ${ }^{8)}$. Note that the present results indicate almost no possibility of penetrating the shock wave for very small particles whose diameter is less than $10 \mu \mathrm{m}$ (not shown in Fig. 10). For instance, minimum initial velocity for 1 and $5 \mu \mathrm{m}$ were $2198 \mathrm{~m} / \mathrm{s}, 472 \mathrm{~m} / \mathrm{s}$ respectively. Moreover, for the former case, the particle penetrating the shock wave immediately reaches the nozzle exit of the arc-heated wind tunnel (see Fig. 2). Such being the case, it is considered that very small particles with the diameter much less than $10 \mu \mathrm{m}$ cannot penetrate the shock wave. 


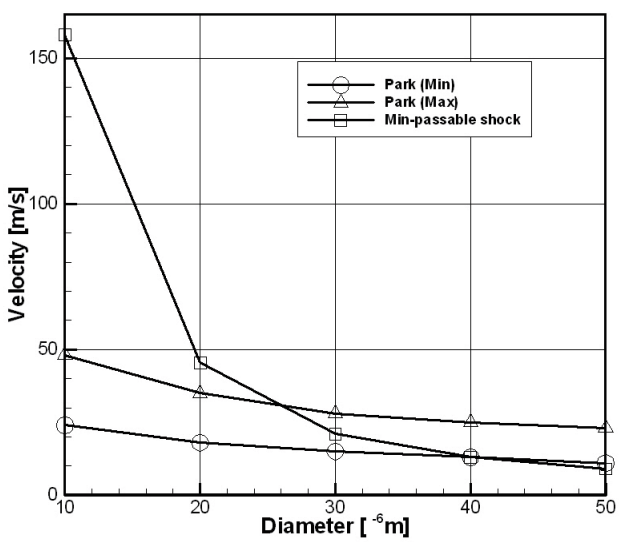

Fig. 10. Minimum ejected velocity for each particle diameter that can reach at the front of a shock wave. Ejected point: $6 \mathrm{~mm}$ from the center axis.

\section{Conclusions}

The behavior of a solid carbon particle ejected from an ablator surface was numerically investigated. Much attention was paid to the classification if a particle can penetrate the shock layer in front of the ablator. The particle behavior was categorized with various kinds of parameters, including ejection point, initial velocity and initial diameter. The conclusions obtained from the present work are as follows:

(I) For some combination of the initial conditions, the particle ejected from an ablator surface gave the trajectory passing close to the point where a particle was identified in the past spectroscopic experiment. The present study indicated that the diameter of the ejected particle was less than $100 \mu \mathrm{m}$. In the region around the measurement point, sublimated gas from the particle in the flow-field reacts with nitrogen and charring gas $(\mathrm{CN})$ is generated, so that its spectra can be seen even in front of a shock wave.

(II) In case of particle diameter less than $20 \mu \mathrm{m}$, very high initial velocity is needed for penetrating the shock wave. Thus, the particle diameter that could be observed in the past experiments is expected to be $20 \mu \mathrm{m}$ or larger.

(III) After penetrating the shock wave, the particle temperature is rather higher than gas temperature. Therefore, the radiation effect from the particle surface increases. This fact may indicate the increase of the particle-radiation heating to the ablator surface in an actual atmospheric entry vehicle.

(IV) Although the surface sublimation causes the decrease of the particle diameter, its cooling power is very small compared with that by convection and radiation. Therefore, it is considered that the sublimation is almost ineffective for heat balance of the particle.

\section{References}

1) Park, C, "Ablation of Galileo Probe Heat-Shield Models in a Ballistic Range", AIAA J. 23, No.2, 1985.

2) Park, C, "Heatshielding Problems of Planetary Entry, A Review", AIAA 99-3415.

3) Schneider, P. J., Dolton, T. A. and Reed, G.W.: "Mechanical Erosion of Charring Ablators in Ground-Test and Re-Entry Environments",AIAA Journal, 6 No.1 (1968), pp.64-72.

4) Lundell, J. H. and Dichkey, R. R.: "The Response of Heat-Shield Materials to Intense Laser Radiation", AIAA-78-138.

5) Yosinaka, T., Mizuno, M. and Morino, Y.: "Detection of Ablator Spallation Phenomena at Arc Wind Tunnel Tests", IEPC-99-025.

6) Kihara, H., Hatano, M., Nakiyama, N., Abe, K. and Nishida, M.: "Preliminary Studies of Spallation Particles Ejected from an Ablator", Trans. Japan. Aero. Space Sci. 49 No.164, (2006), pp.65-70.

7) Raiche, G.A. and Driver, D.M.: "Shock Layer Optical Attenuation And Emission Spectroscopy Measurement During Arc Jet Testing With Ablating Models", AIAA-2004-825.

8) Park, C., Raiche. G.A. and Driver, D.M, "Radiation of Spalled Particles in Shock Layers", AIAA-2004-1349.

9) Davis C. B. and Park C.: "Trajectories of Solid Particles Spalled from a Carbonaceous Heat Shield", AIAA-82-0200.

10) Tran, H. K., Johnson, C. E., Rasky, D. J., Hui, F. C. L., Hsu, M.-T., Chen, T., Chen, Y. K., Paragas, D. and Kobayashi, L.: "Phenolic Impregnated Carbon Ablators (PICA) as Thermal Protection Systems for Discover Missions", NASA Technical Memorandum 110440.

11) Yamada, T., Abe, T., Yokota, R., Ishida, Y., Ogasawara, T., Suzuki, T. and Fujita, K.: Symposium of Fluid Mechanics and Astrodynamics, 2007.

12) Takahashi, Y., Kihara, H. and Abe, K.: "Numerical Investigation of Thermochemical Nonequilibrium Flow Field in a $20 \mathrm{~kW}$ Arc Heater Coupled with Electric Field Calculation", Rarefied Gas Dynamics: 26th International Symposium, pp.883-888.

13) Ishimaru, S. and Nishida, M.: "Numerical Analysis of Gas-Solid Two-Phase Flow Process in Exhaust Plumes", Transactions of the japan society for aeronautical and space science, 31 No. 94, (1989), pp.195-207.

14) Chase, M. W. Jr., Davies, C. A., Downey, J. R. Jr., Frurip, D. J., McDonald, R. A. and Syverud, A. N.: "JANAF Thermochemical Tables" Third edition, Journal of Physical and Chemical Reference Data, 14 (1985)

15) Henderson, C. B.: "Drag Coefficients of Spheres in Continuum and Rarefied Flows", AIAA Journal, 14 No.6, (1976), pp.707-708.

16) Carlson, D. J. and Hoglund, R. F.: "Particle Drag and Heat Transfer in Rocket Nozzles", AIAA Journal, 2 No.11, (1980), pp.1980-1984.

17) Paulmier, T., Balat-Pichelin, M., Le Queau, D., Berjoan, R., Robert, J. F.: "Physico-chemical behavior of carbon materials under high temperature and ion irradiation", Applied Surface Science 180 (2001), pp.227-245. 